Ittishal Educational Research Journal

July 2020, Vol. 1, No. 01, p. 40 - 50

http://journal.ittishal.net/index.php/ierj

DOI: 10.51425/ierj.v1i1.1

\title{
I-Pad Based Arabic Language Teaching Method in Al- Azhar Cairo Islamic Senior High School Palembang Indonesia
}

\author{
Diah Sakinah \\ Al Azhar Cairo Islamic School, Palembang, Indonesia \\ diskah_88@yahoo.com
}

\begin{abstract}
We are now living in $21^{\text {st }}$ century, the century of development of technology, datas and digital trends. Several kinds of job have been replaced by their digital versions. Electronic based learning method has been a familiar skill found at majority of school in this century. The motive behind this method is to reduce the illiteracy of technology among students by introducing them how to use some technological devices effectively so they can understand, evaluate and participate on it. In addition for the method of Arabic teaching in Indonesia should be changed into e-learning based as a way to face recent challenges and problems while teaching. One of those problems is the less attention from students to learn Arabic language due to some difficulties of Arabic language teaching books and its material, as well as limited devices they can use. It's known that this Islamic boarding school is the only school signed up its name on iTunes $U$ platform. This paper is a descriptive qualitative research which took respondents of 10 students of Al-Azhar Cairo Islamic Senior High school Palembang, Indonesia. The data are collected based on interviewing, informing and collecting files. The data collection is completed using Miles and Huberman's data collection method in descriptive explanation. Finally this research concluded that the iPad based learning method used by this school did impacted well on gaining student's attention in learning Arabic language including its basic skills (listening, reading, speaking, and writing)
\end{abstract}

Keywords. teaching; Arabic language; iPad based learning 


$$
\begin{aligned}
& \text { عليم الغنة الـ ربية }
\end{aligned}
$$

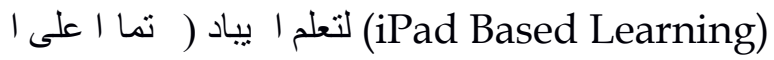

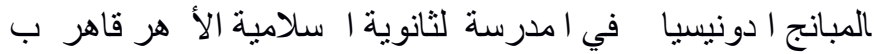

\section{لخص}

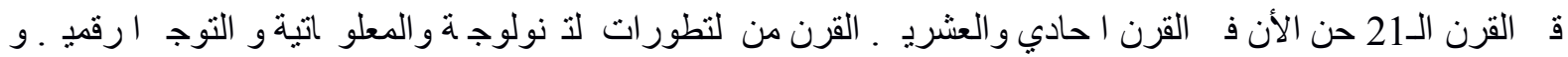

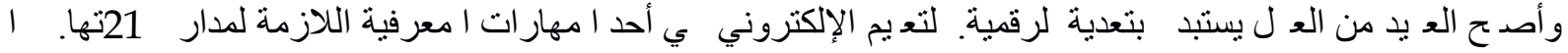

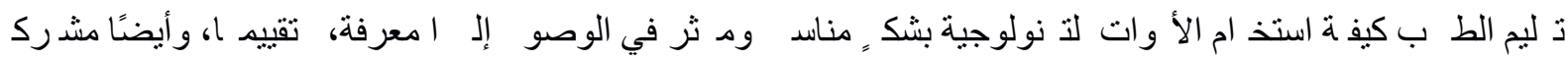

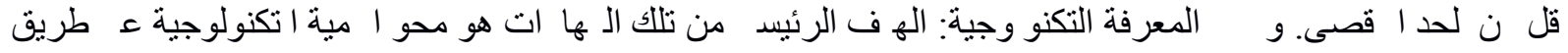

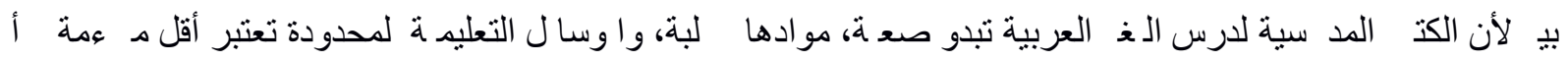

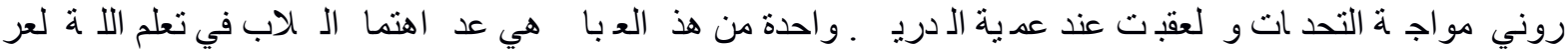

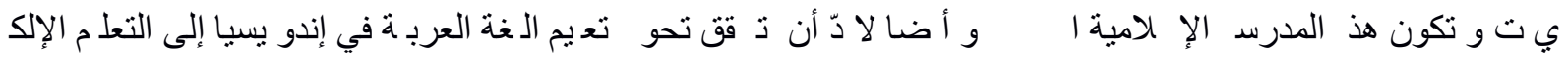
تيونز (iTunes

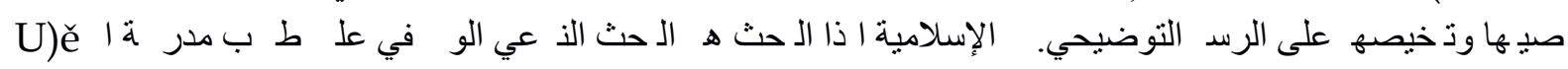

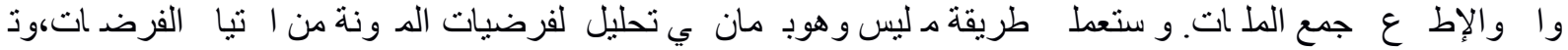

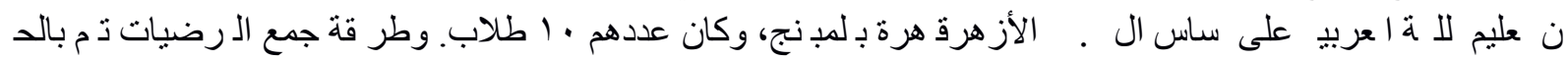

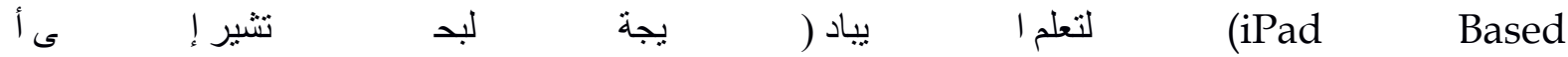

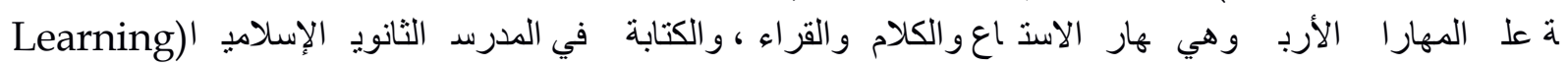

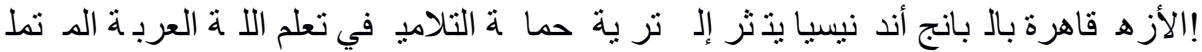

i)لكلمات لرئيسي :تعليج, للغة لعربية، التعلم لأيباد(iPad learning) 


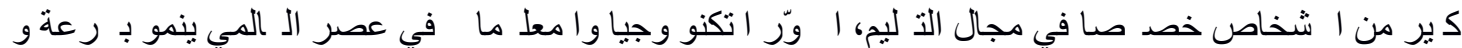

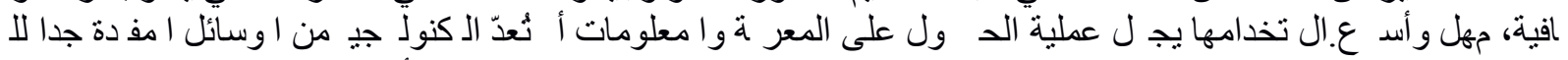

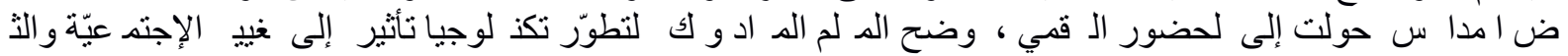

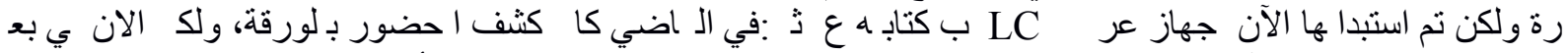

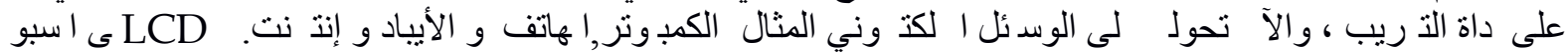

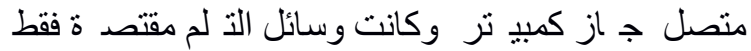

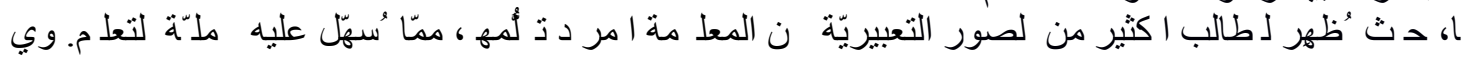

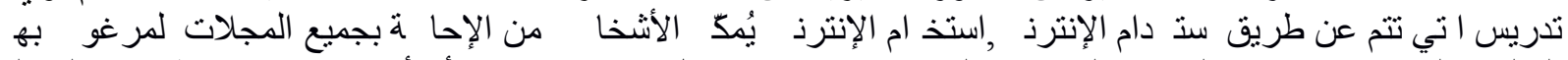

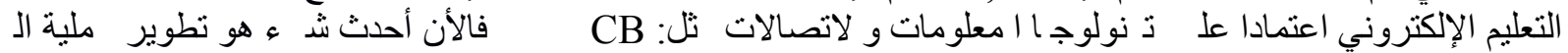

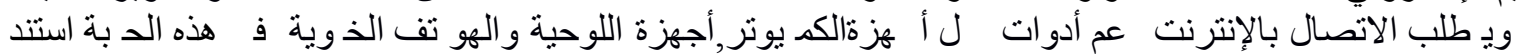

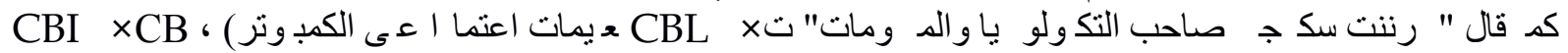

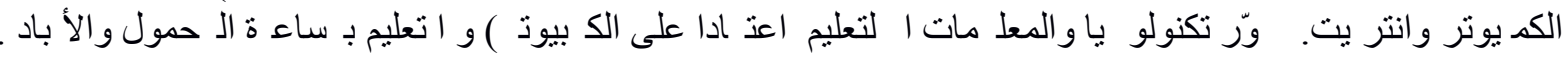

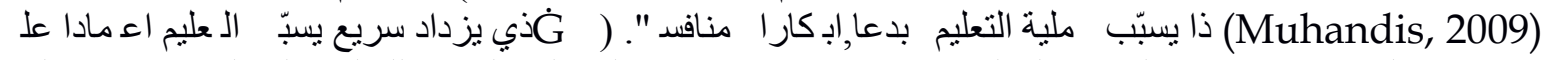

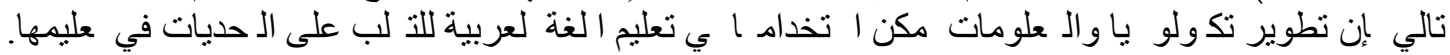

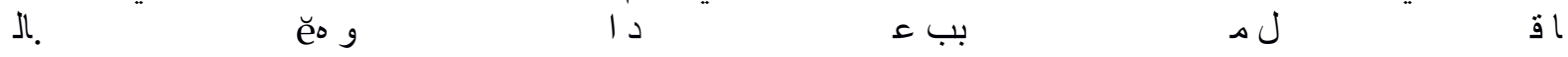

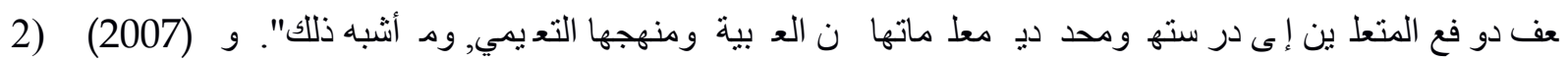

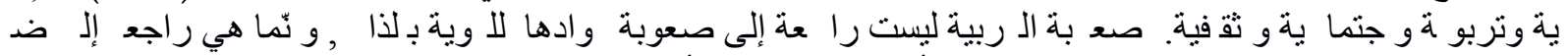

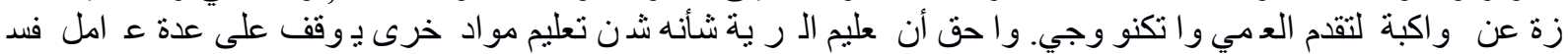

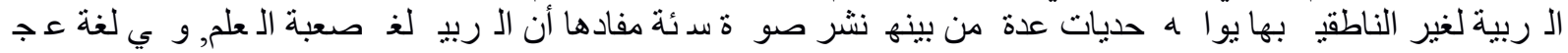
تعليم اللغ الغيز

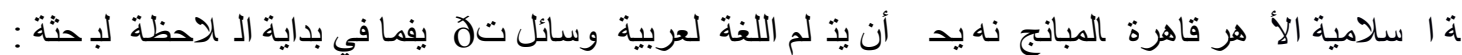

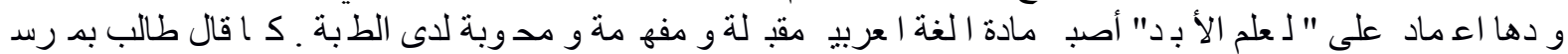

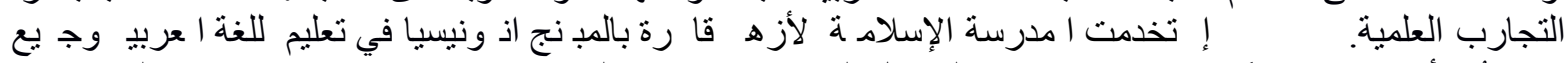

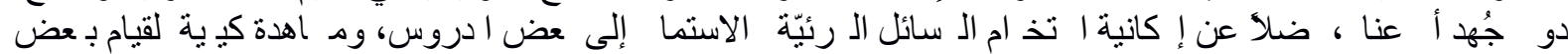

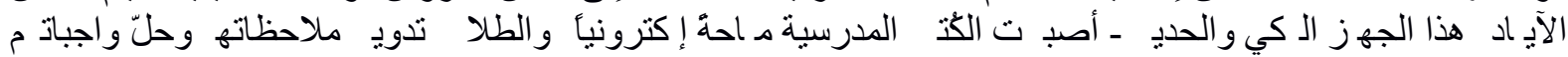

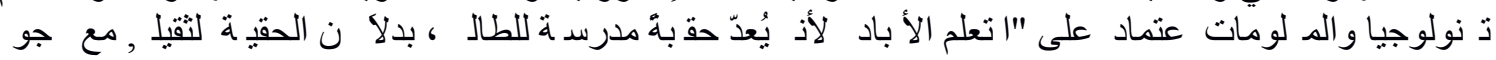

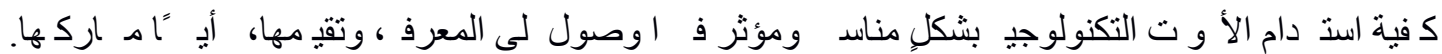

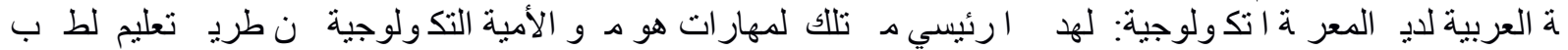

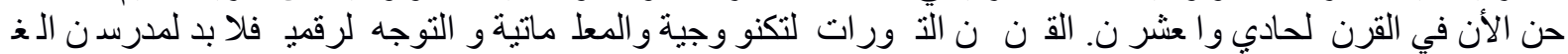

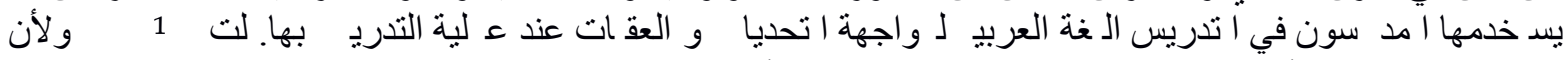

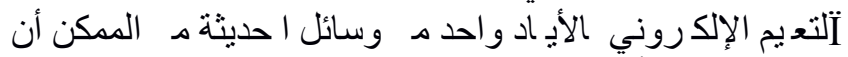

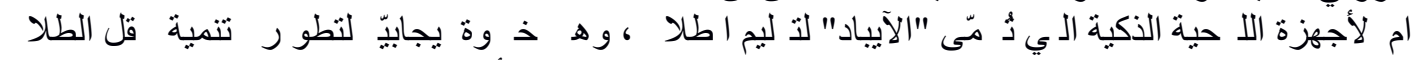

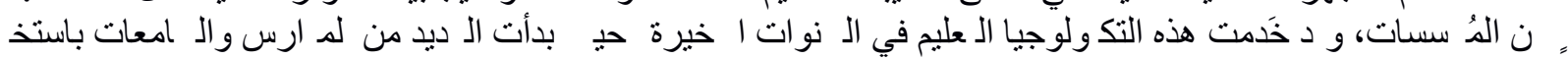

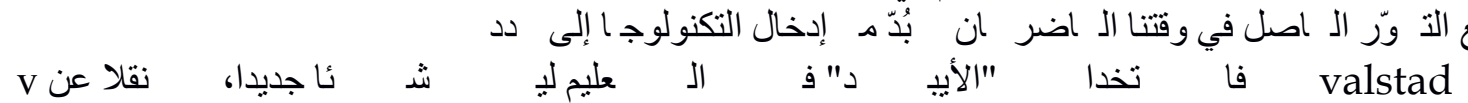

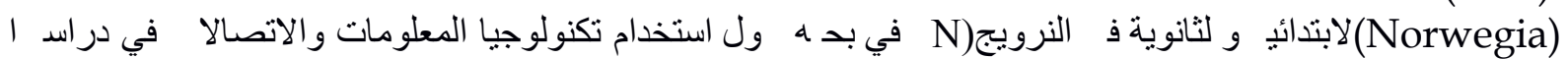

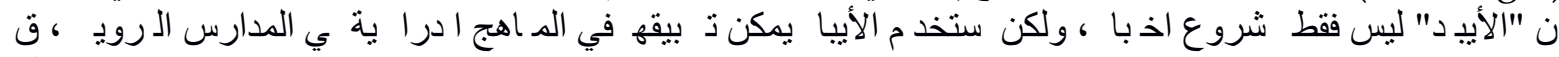
ير إلى

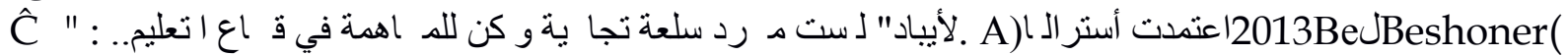

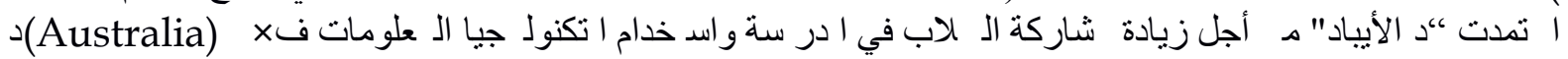

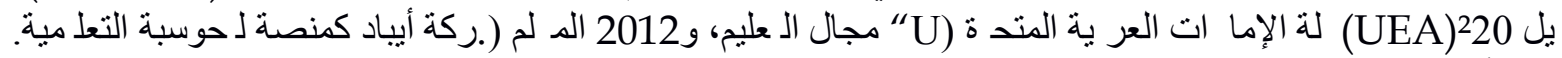

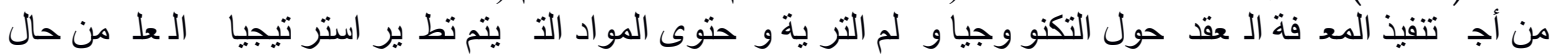
تم هذا الت بي (Eric, 2014) . الت ليم والمدرس, هي: لتعلم الآباد" ن فو ائد است دام تكنول جيا الد لومات "ال 


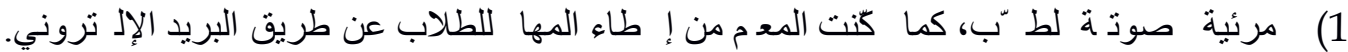

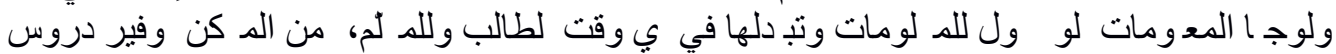

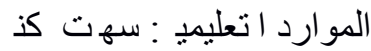

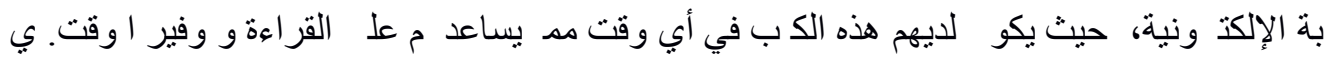

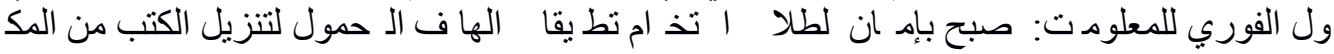

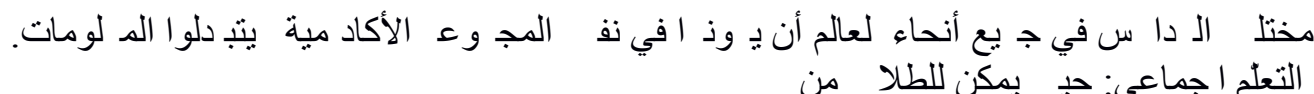

اسة للط ب في جمع نحاء اعالم ن أي مكن عبر لتعلم عر الإنترنت وبالتالي تقلي ت تكايف التنق.

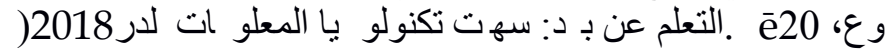

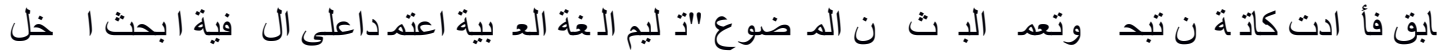

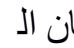
على الب الب

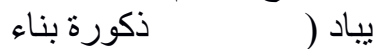
لتعلم 1 (iPad

Based المبانج اذونيسيا. في امدرسة لثانوية ا سلامية الأ هر قاهر ب(Pearning

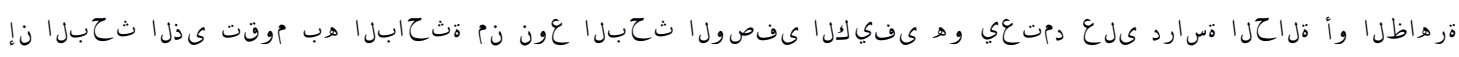

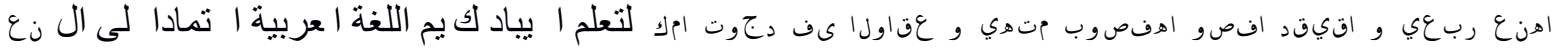

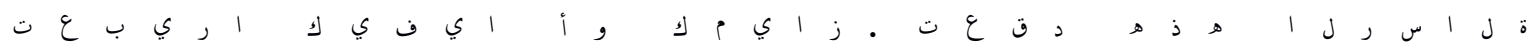

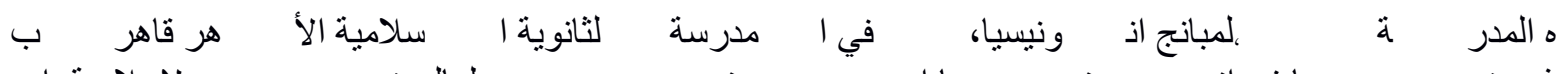

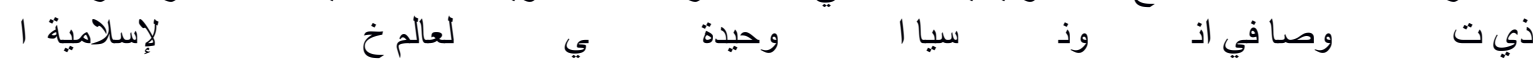

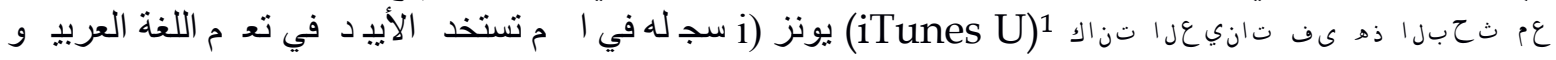

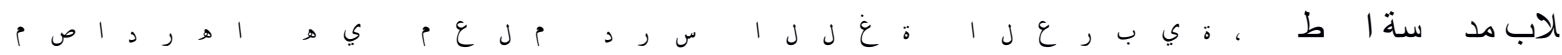

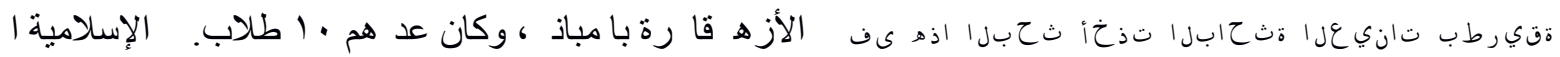

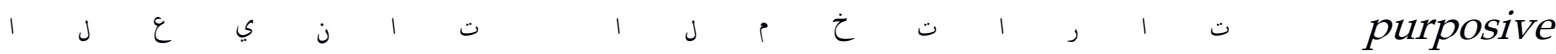

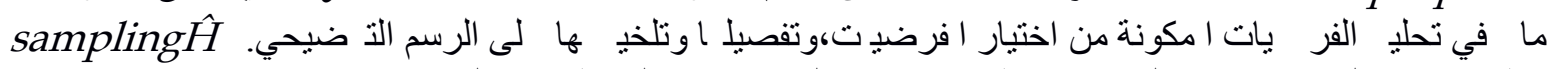

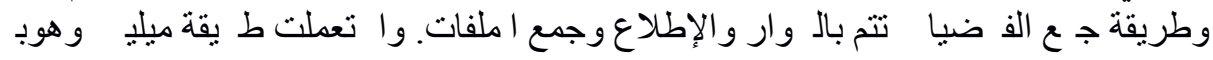

3. ريف ت ليم الـ غة العربي اعتمادا على الت لم الأيباد ي المد سة لثانوية الإسلامية الأزهر الفقا رة با ل المبانج.

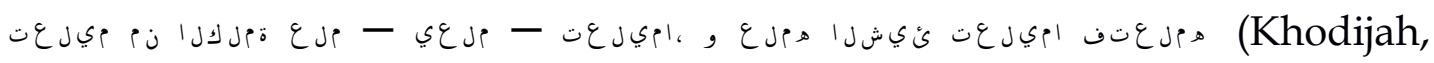
2014)

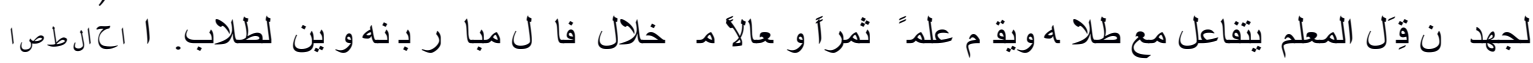

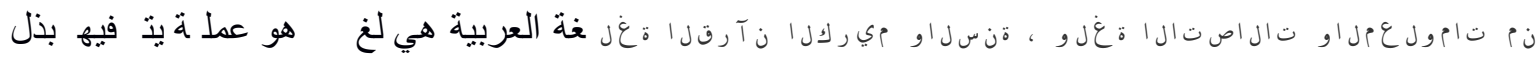

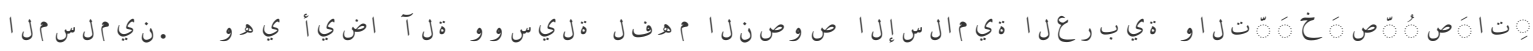

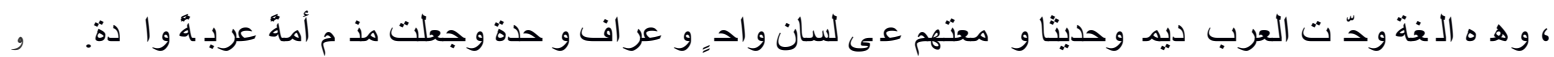

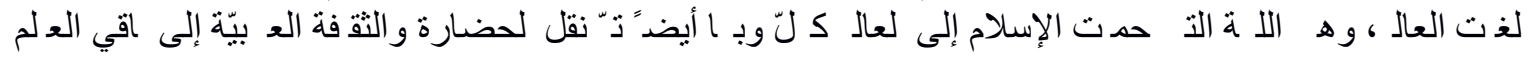

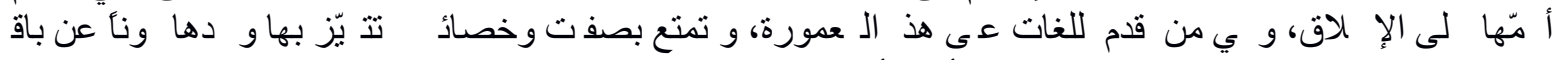

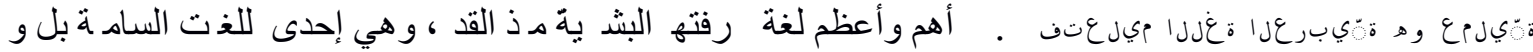

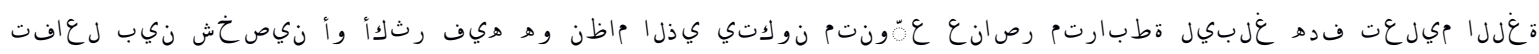
( tablet

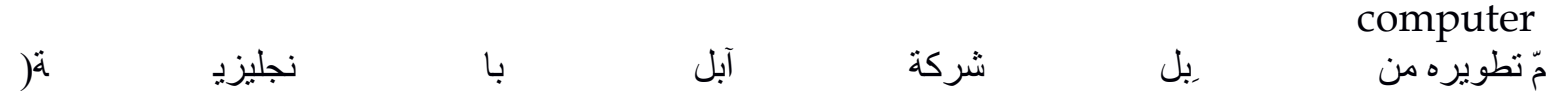

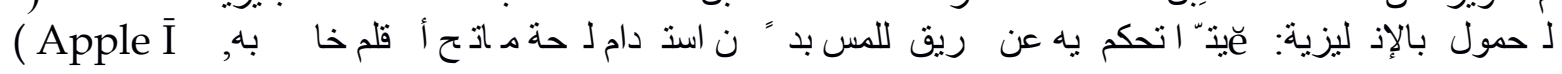




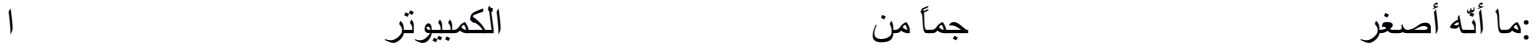

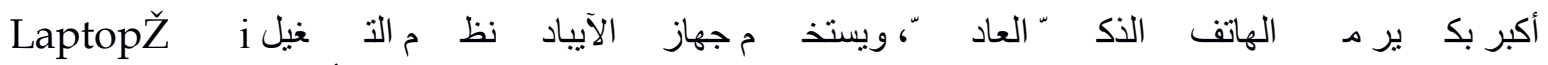

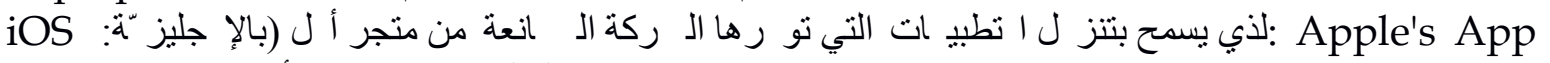

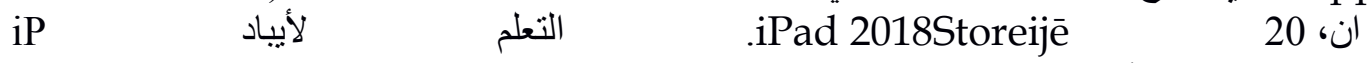

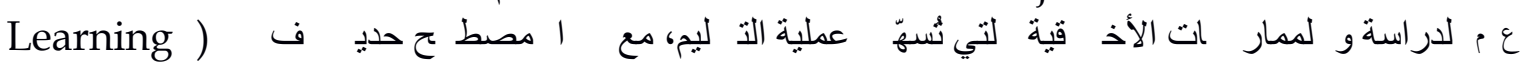

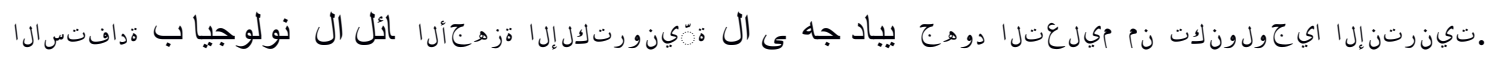

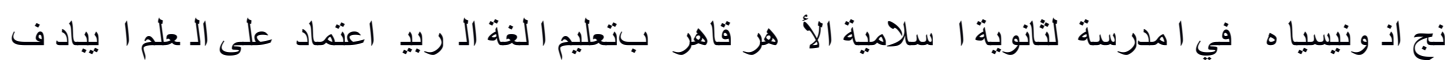

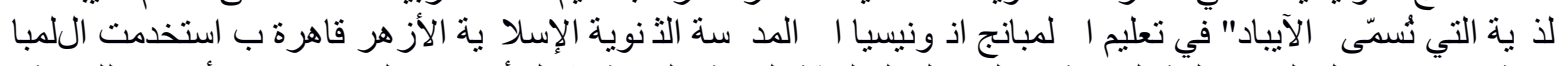

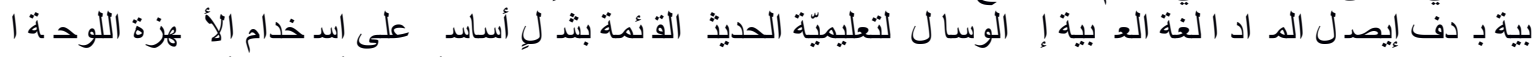

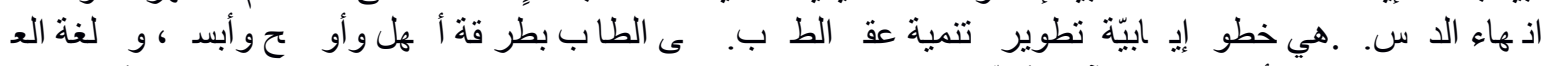

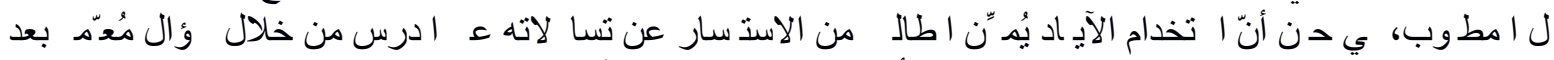

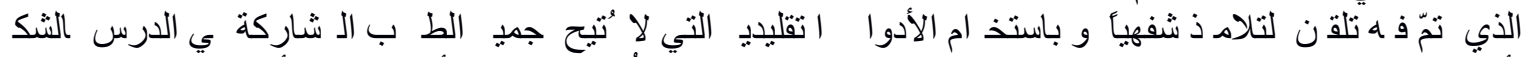

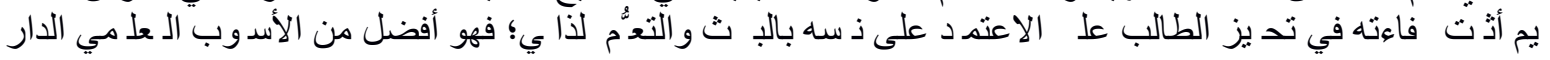

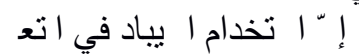

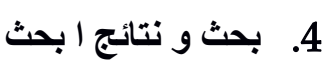

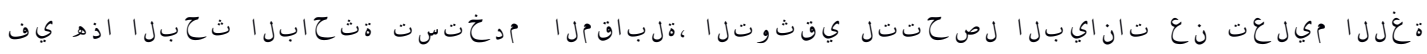

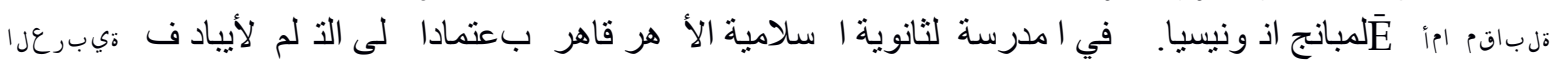

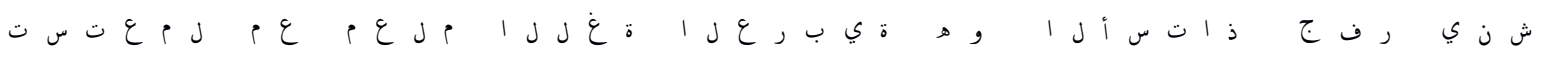

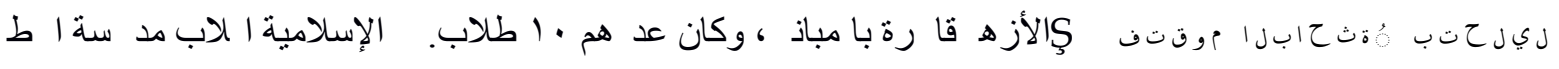

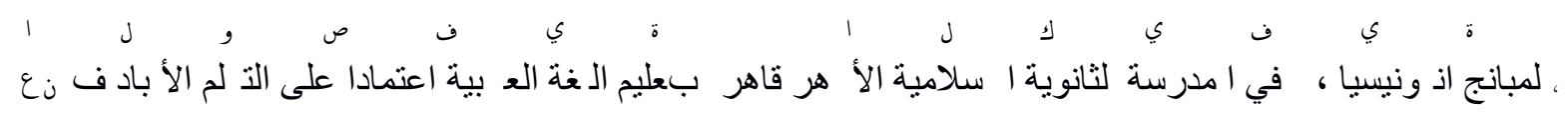

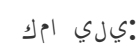

\section{لمبانج. تعليم الغة الـ ربية اعتم دا على ا تعلم الأبا في الم رسة الـ انو ة الإسلامه الأزهر الفقا رة با}

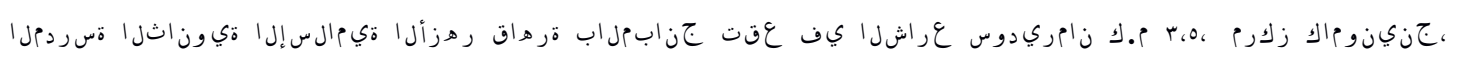

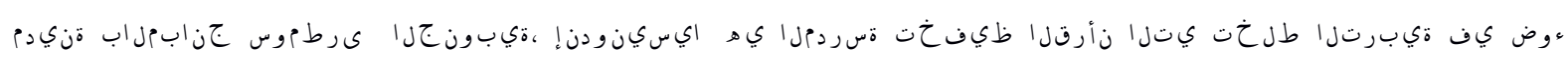

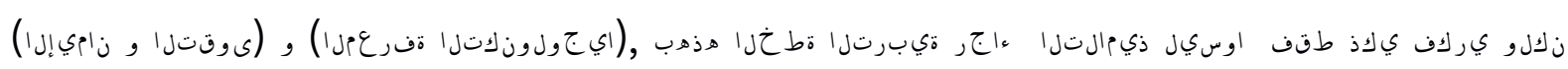

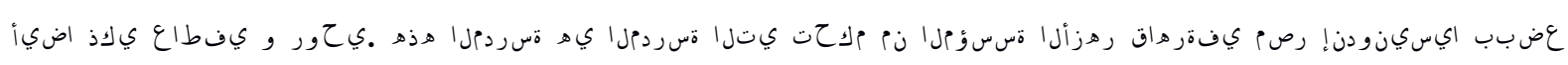

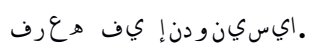

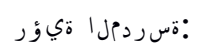

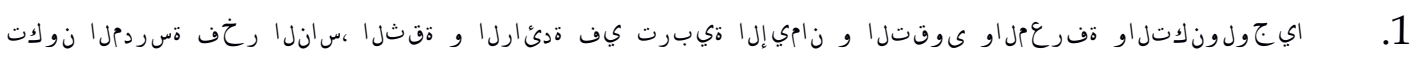
1 1

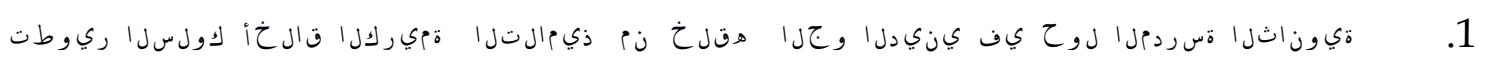

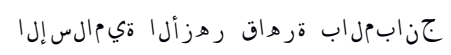
2. 5 8

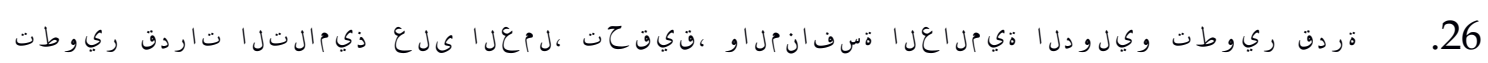

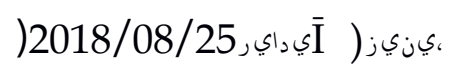

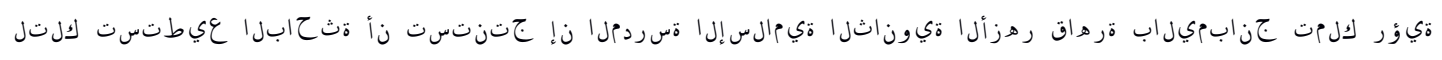

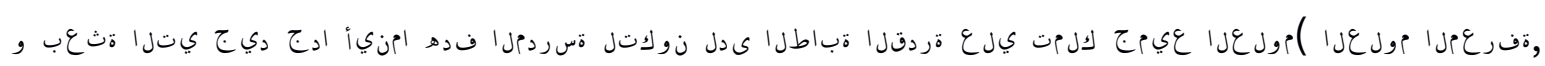




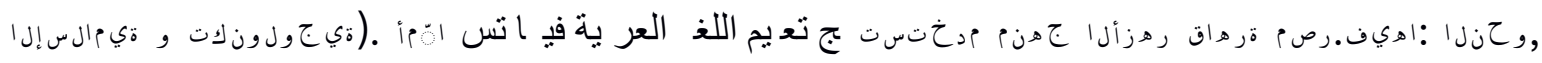

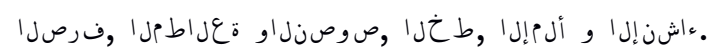

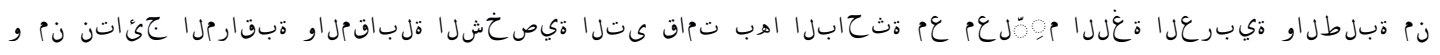

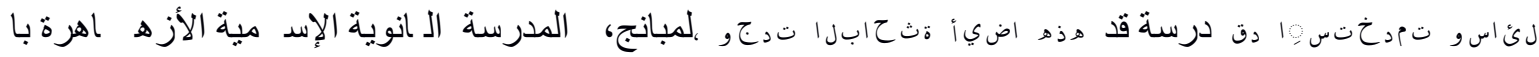

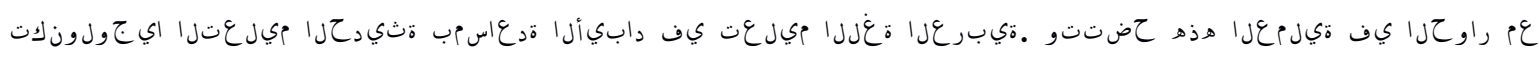

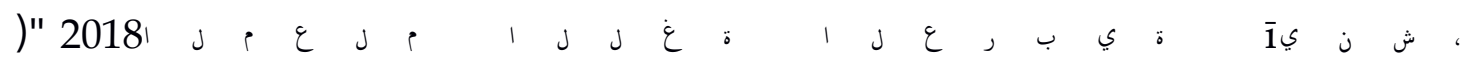

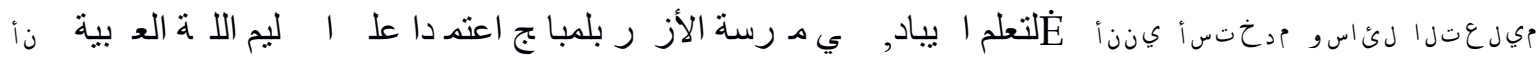

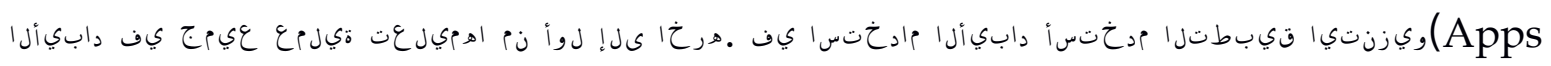

iTunes

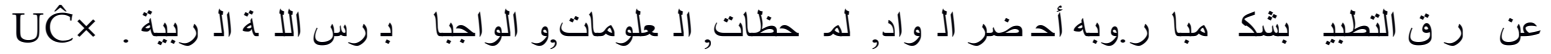

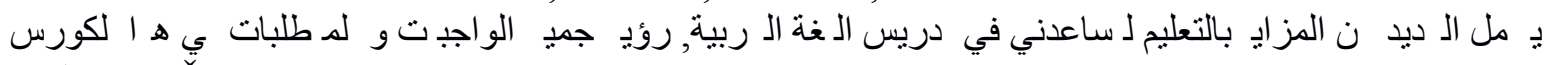

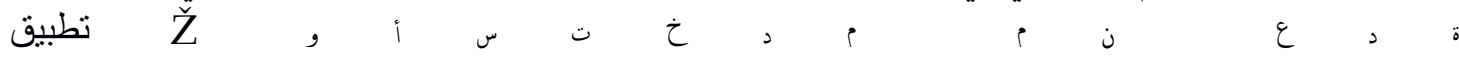

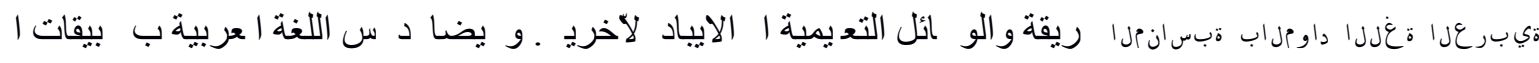

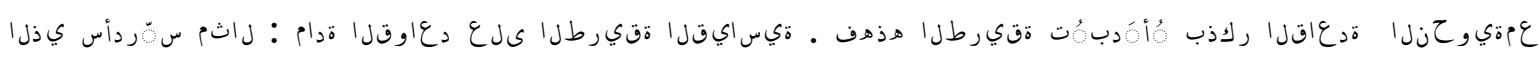

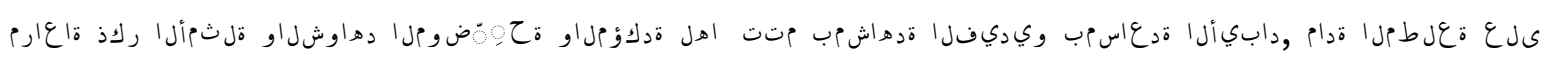

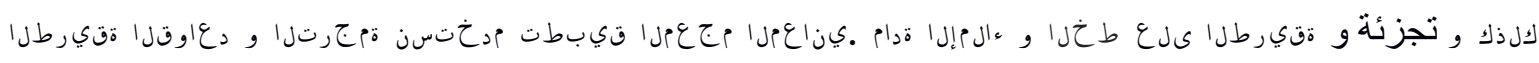

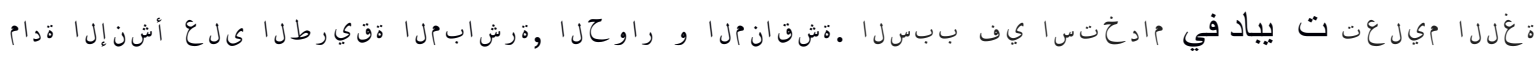

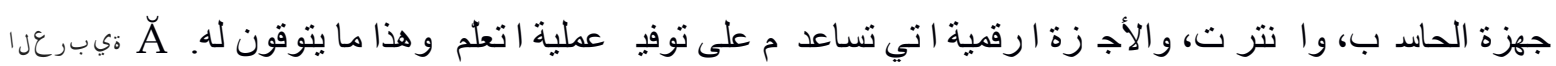

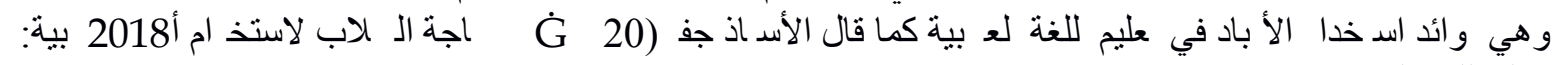
1.

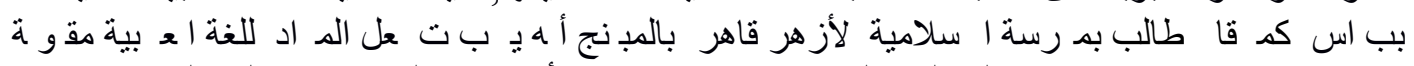

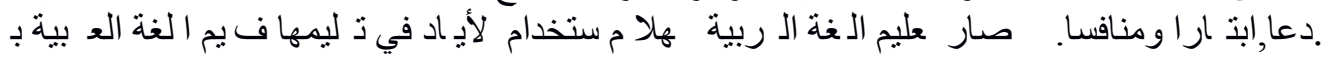

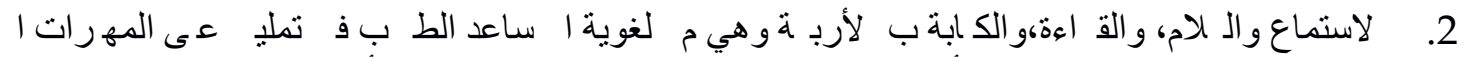

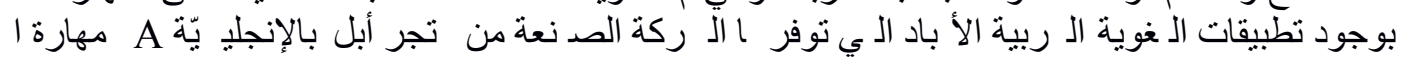

Apple's App Store: ) 3.

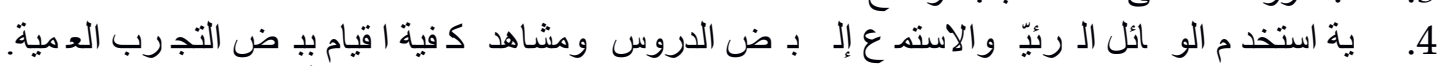

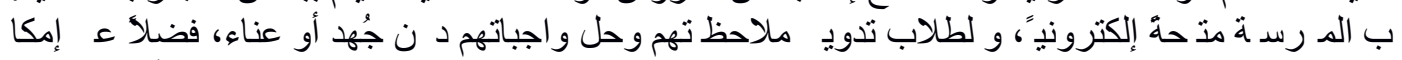

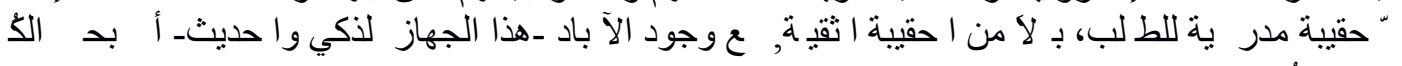

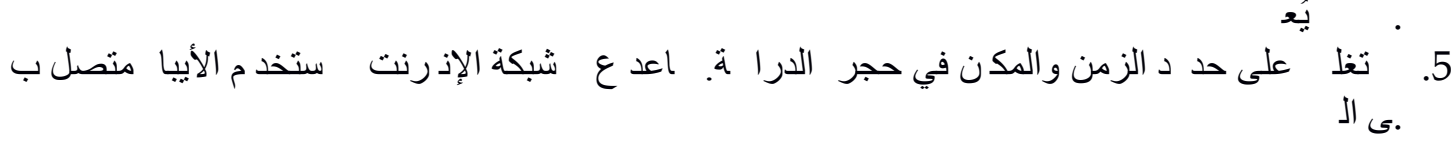

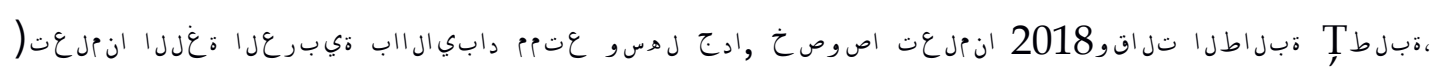
.

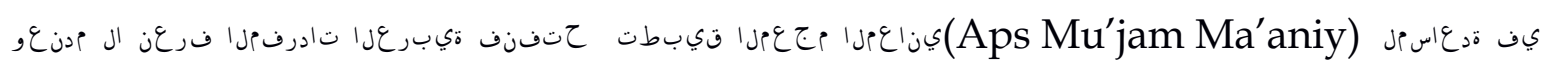

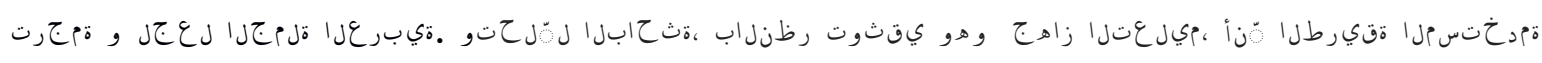

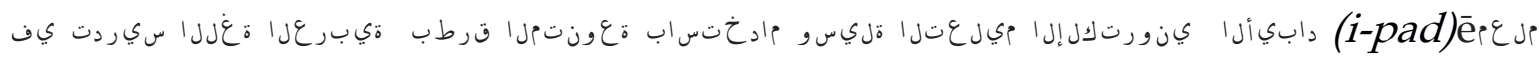

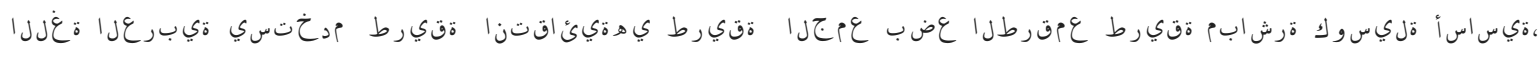

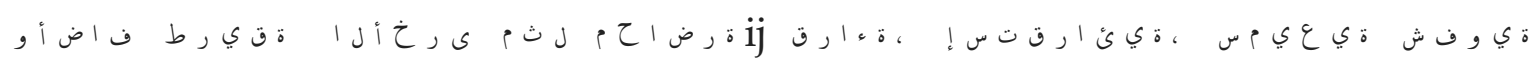




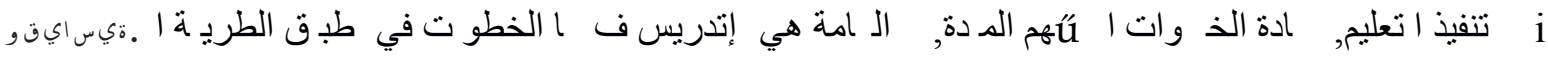

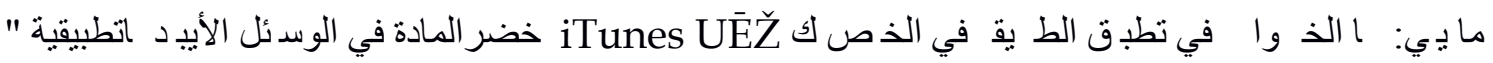

القياسية فالخطوات رطب دعاوقلا ميرعت

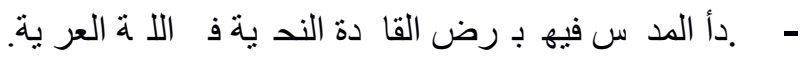

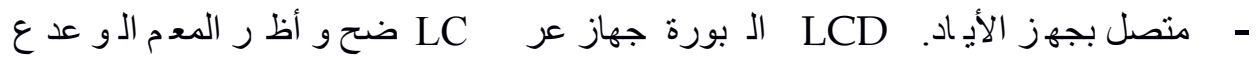

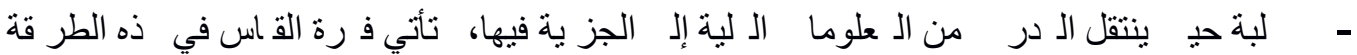

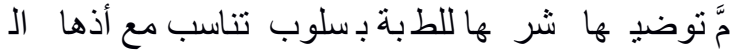

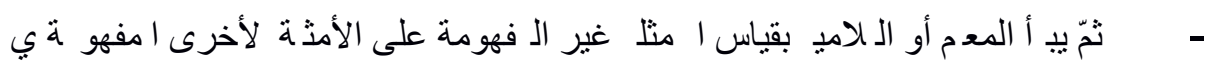

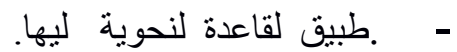
الطري ة الاستنباطية تُسمى بالاستقر ائية أيضأ:

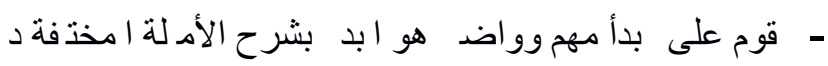

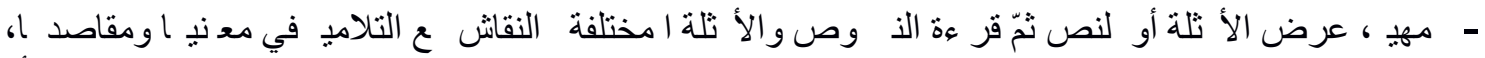

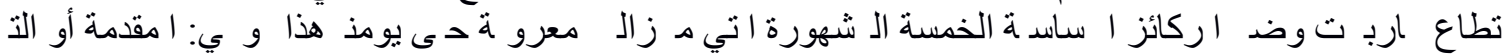

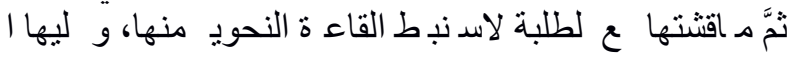

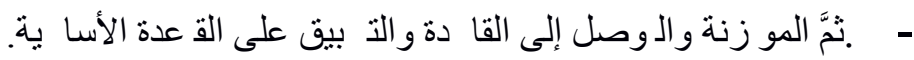

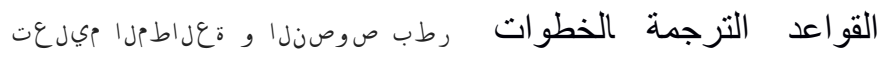

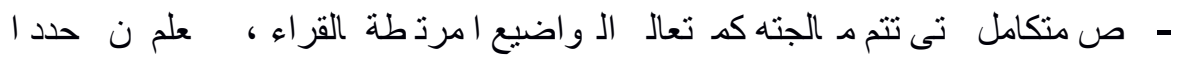

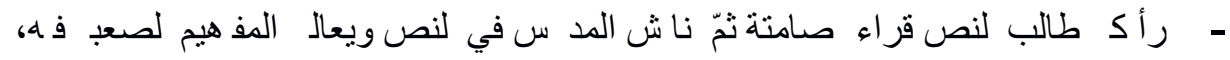

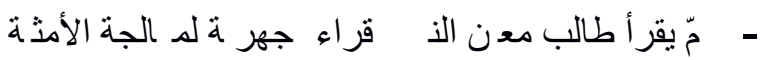

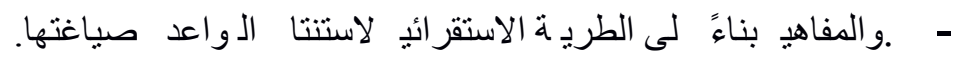

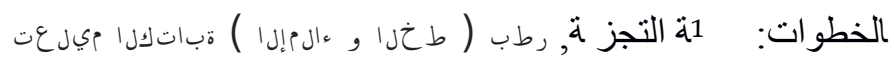

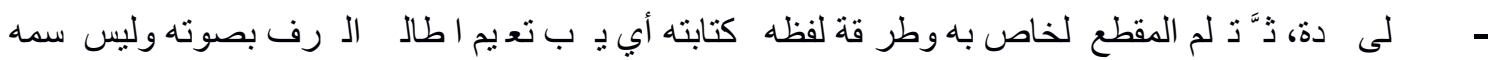

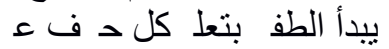

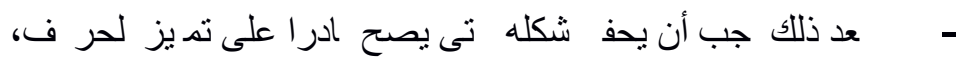

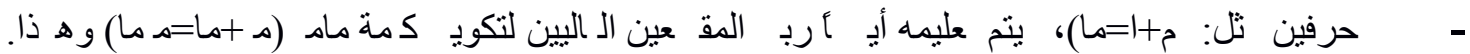

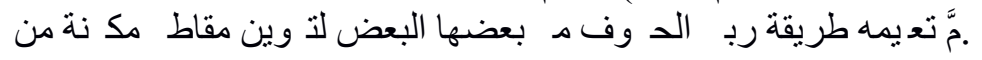

تخدام ا معلم ت تمن ) بيقات

(Arabic -

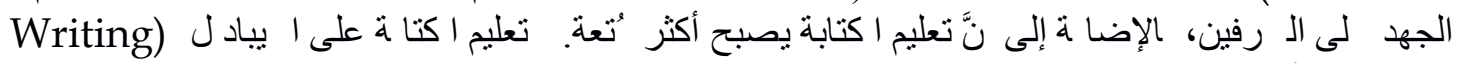

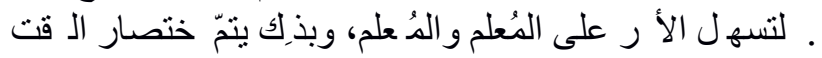

$$
\begin{aligned}
& \text { قة المباثدة , فالخطو ت: رطب ( أشن إل × عالكلا عيلعت }
\end{aligned}
$$

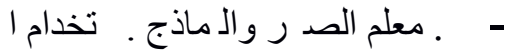

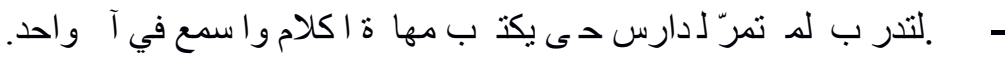

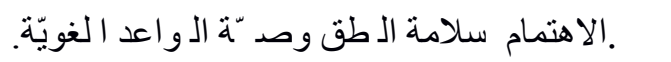

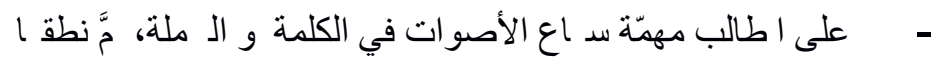

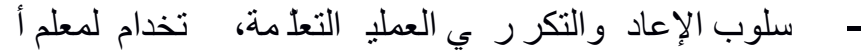

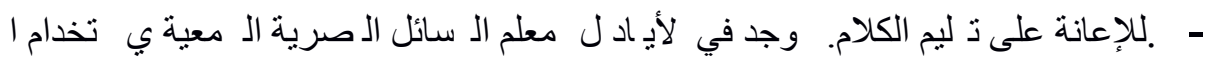




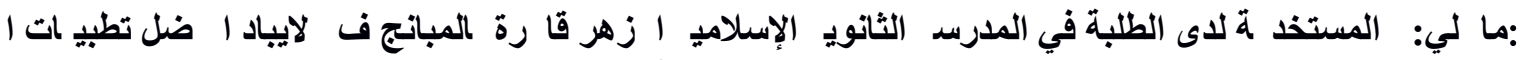
1

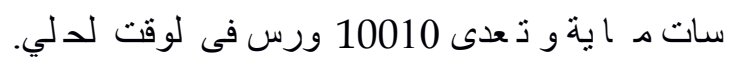

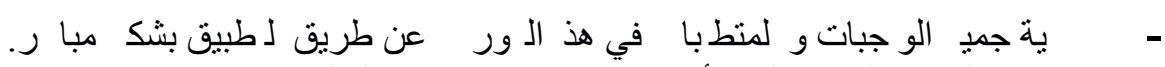

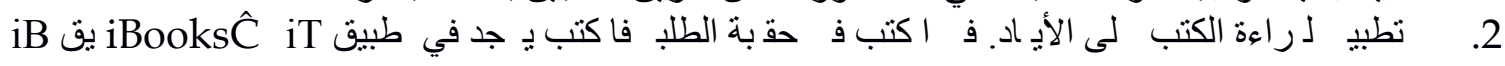
\lrcorner iTunes U.

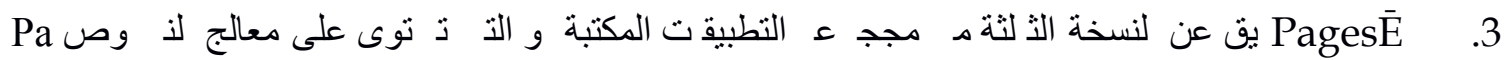

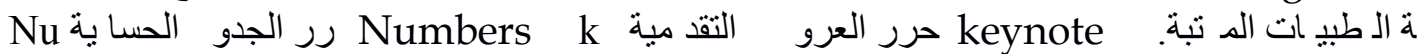

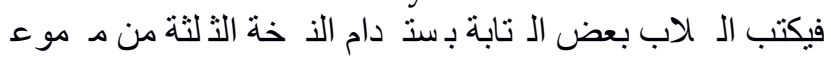

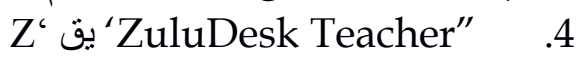

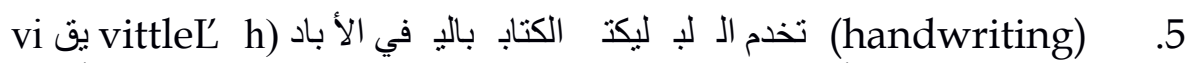

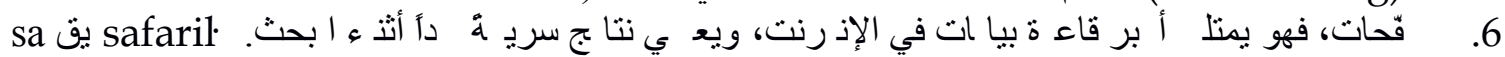

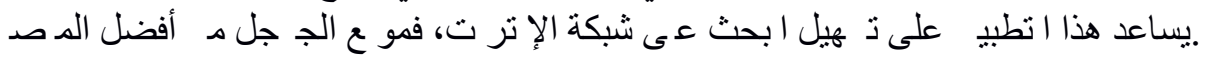

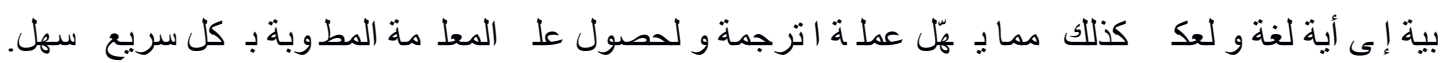

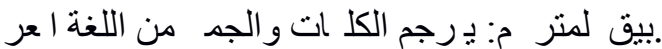

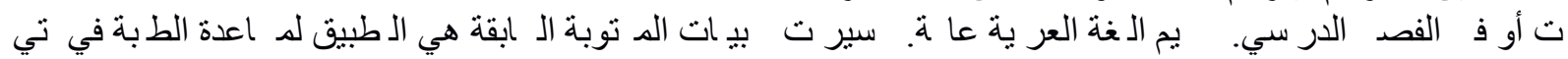

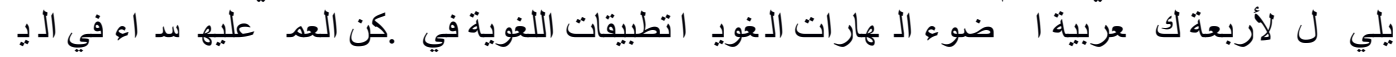

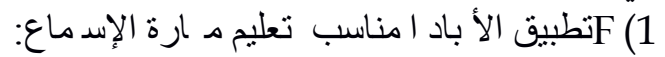

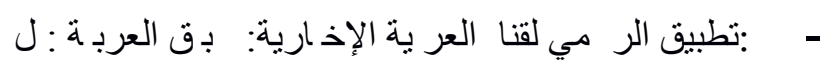

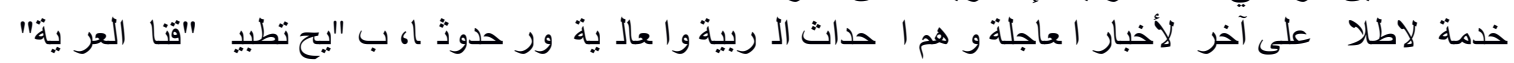

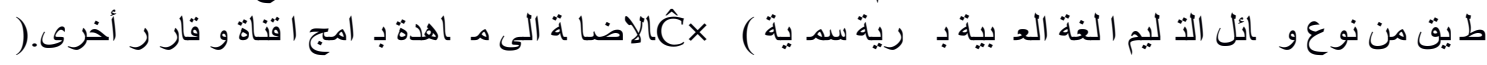
yo وب

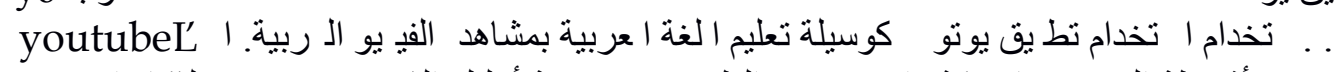

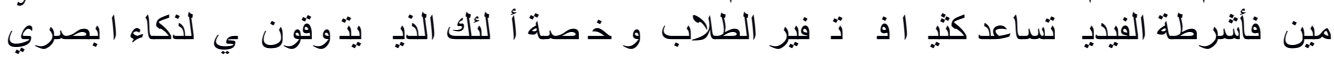

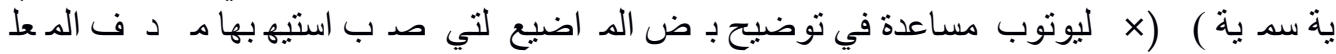

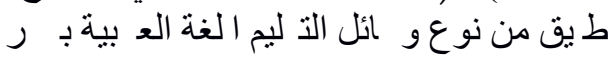

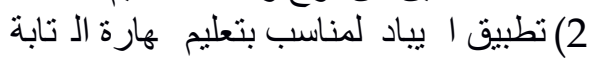

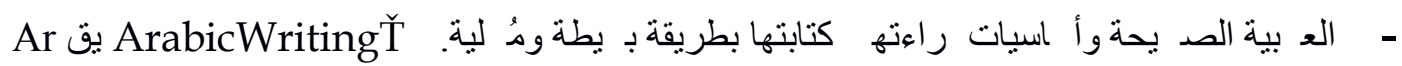

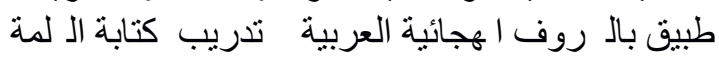

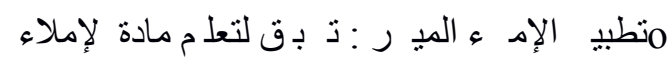

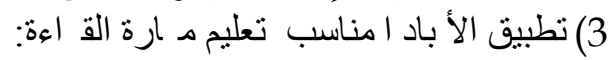

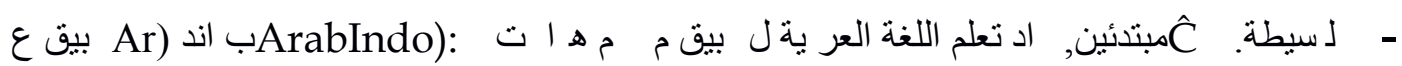

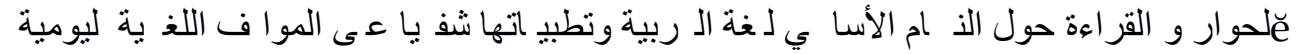

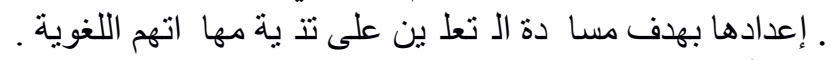

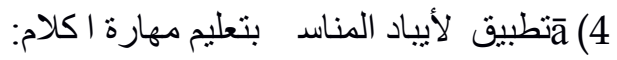

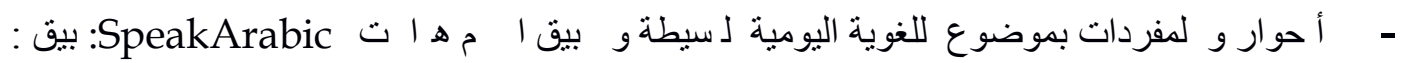

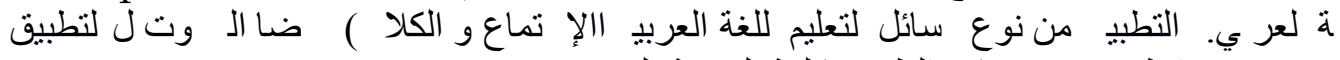

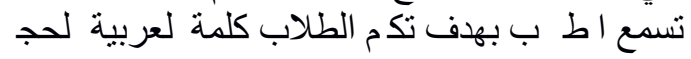

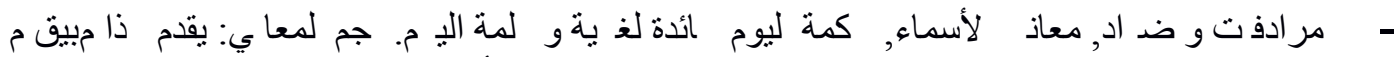

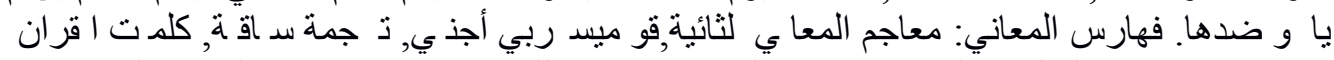

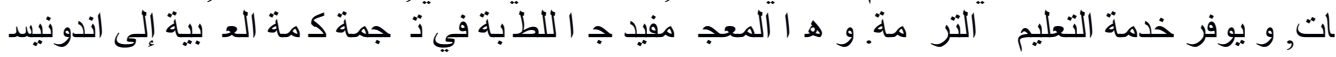

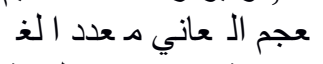

5) .اب ترفي ية وقصد تعليمة متنوء بالغة العر ية. بيق ل يق عبة عليمية الغة اعربية: قدم ذا ت 


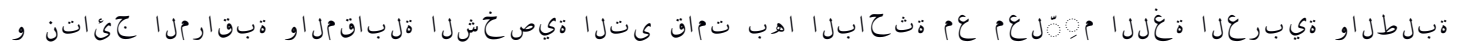

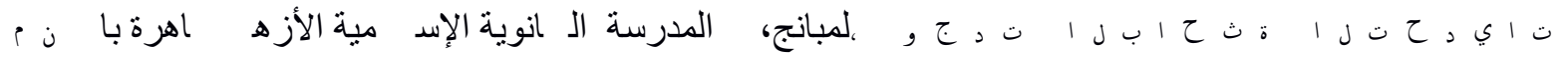

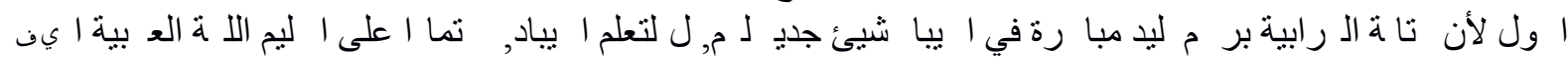

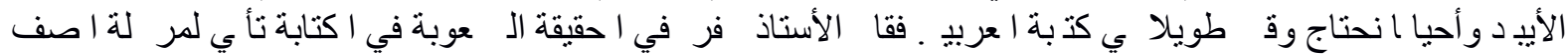

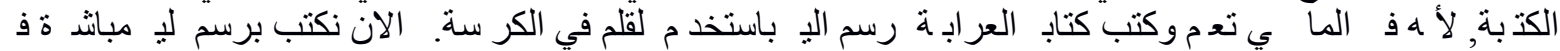

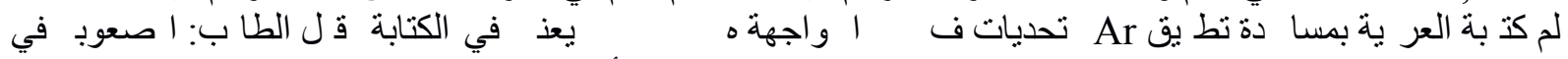

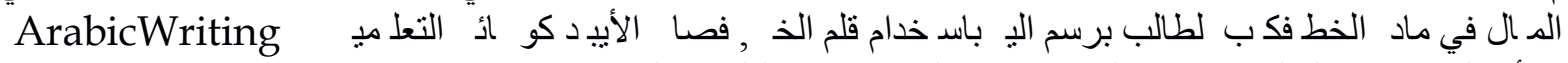

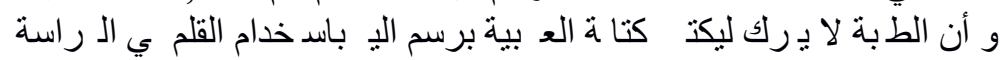

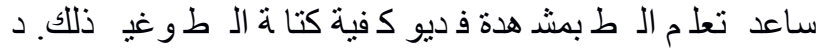

\section{5}

الخلاصة:

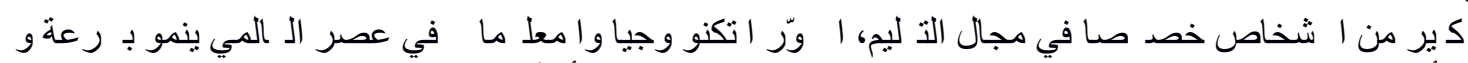

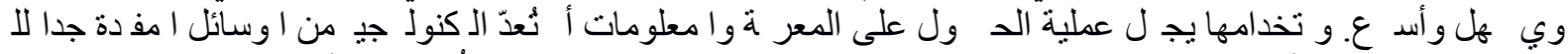

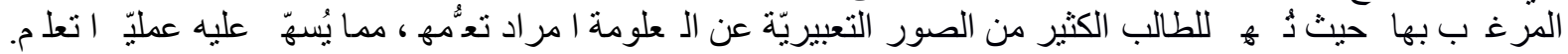

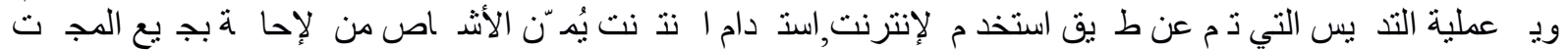

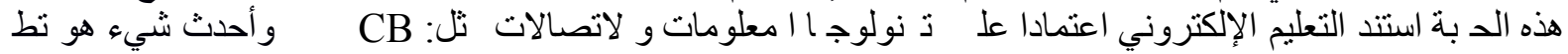

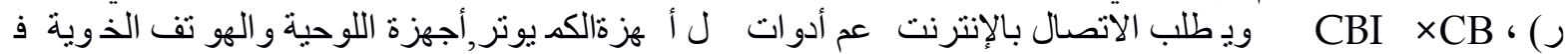

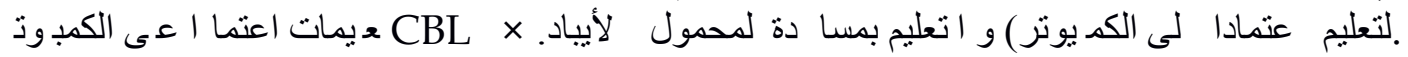

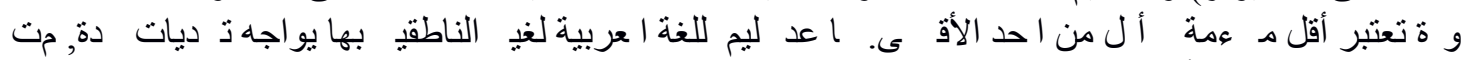

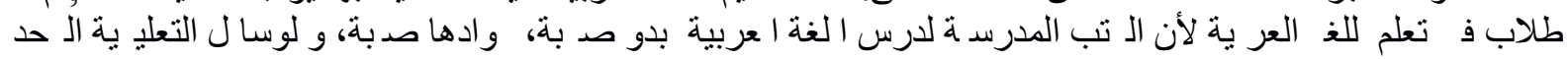

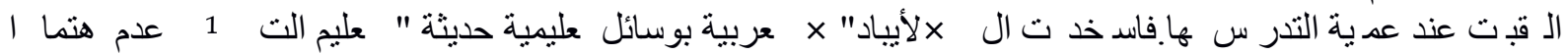

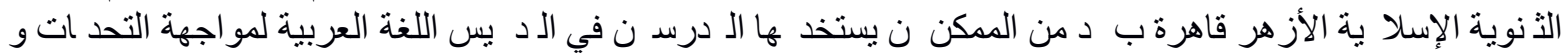

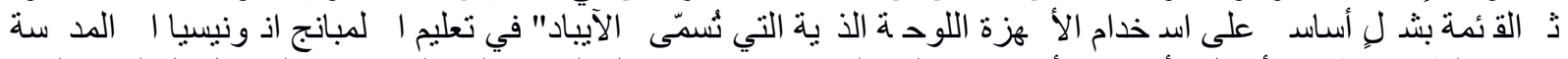

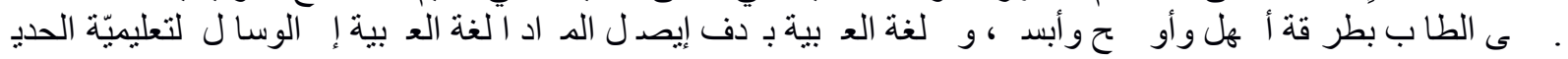

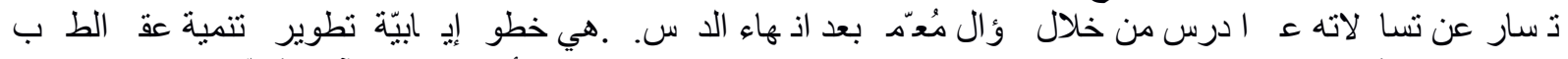

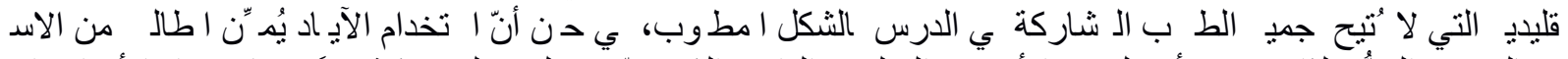

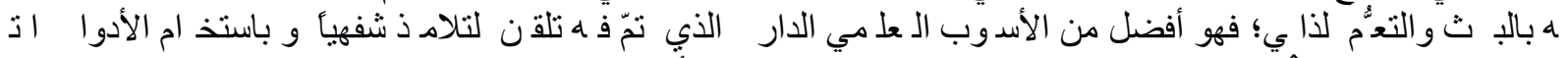

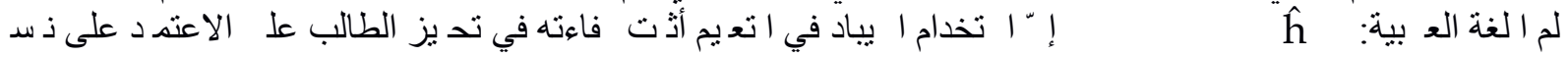

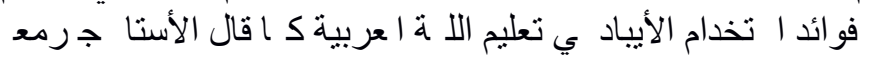

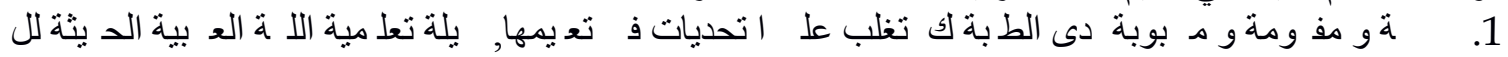

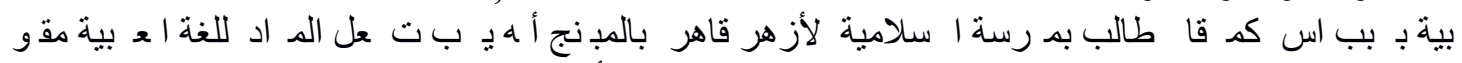

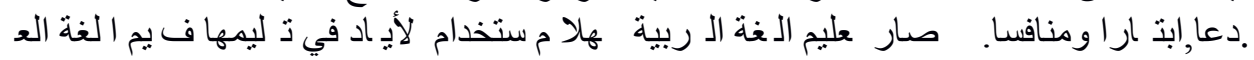

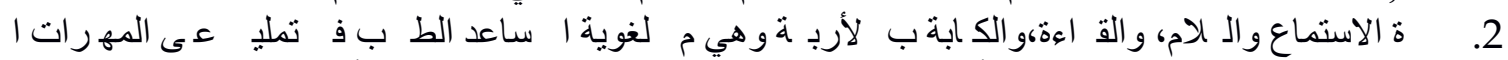

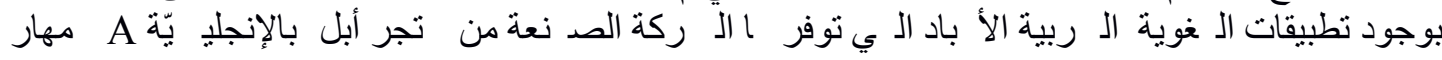

Apple's App Store: )

$$
\text { 3. }
$$

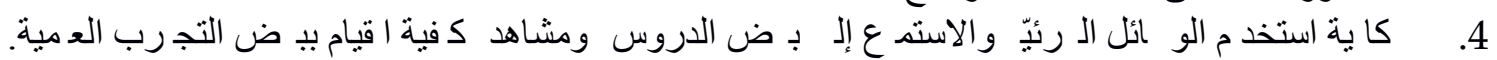

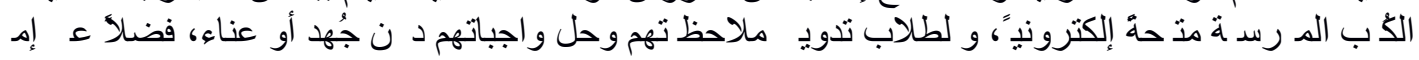

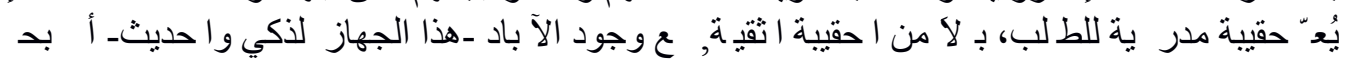

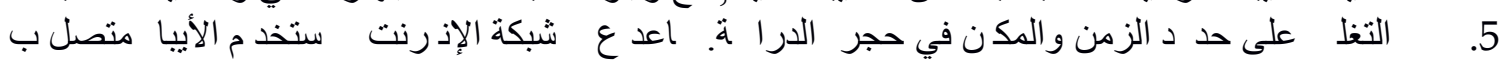

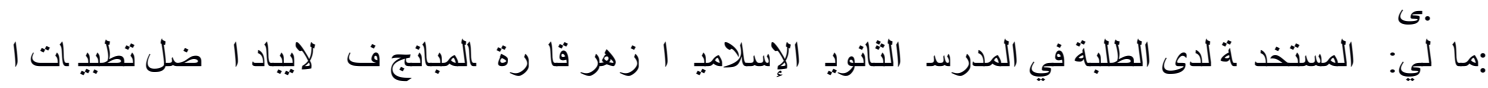

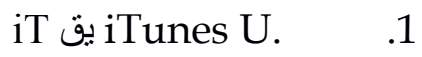
iB يقiBooks.

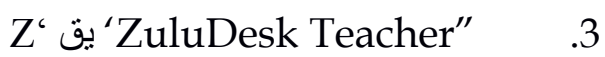
vi يق vittle.

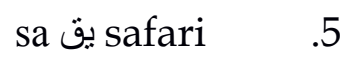


6. بيق الـ ترجم

7.

yo 8

Ar ArabicWriting .9

10.

11.

S بيق SpeakArabic . 12

13. عجم اله اني بيق م 


$$
\text { لمراجع }
$$

Abdul, R., \& Azkia, A. M. (2018). Desain Perkuliahan Bahasa Arab Melalui Google Classroom. Jurnal Arabiyat, 5(1).

Ada, F. U. (2015). Rancang Bangun Aplikasi Media Pembelajaran Bahasa Arab Berbasis Multimedia. 5 Firmansyah Udi Ada. 2015. Rancang Bangun Aplikasi MeJurnal Teknologi dan Sistem Infomasi, 2(1).

Eric, A. K. (2014). Padagogi dalam Praktik: Sebuah Model m-Learning dalam Pembelajatan Bahasa. Prosiding Seminar Internasional.

Khodijah, N. (2014). Dalam Psikologi Pendidikan. Jakarta: Raja Grafindo Persada.

Koderi. (2014). Pembelajaran Bahasa Arab Berbasis Media iPad (i-Learning). Jurnal Al Bayan, 6(2).

Mahyudin, R., Alwis, N., \& Wahyuni, S. (2016). Pembelajaran Bahasa Arab Berbasis Teknologi Informasi dan Komunikasi Di Kota Padang. 5 Ritonga Mahyudin., Nazir Alwis., Sri Wahyuni. 2016. Pembelajaran BahJurnal Arabiyat, 3(1).

Muhandis, A. (2009). Metode dan Media Pembelajaran Bahasa Arab Berbasis Internet di Era Teknologi Informasi. Jurnal Pemikiran Alternatif Kependidikan, 14(3).

Muhbib, W. A. (2007). Tantangan dan Prospek Pendidikan Bahasa Arab di Indonesia. Jurnal Afaq Arabiyyah, 2(1).

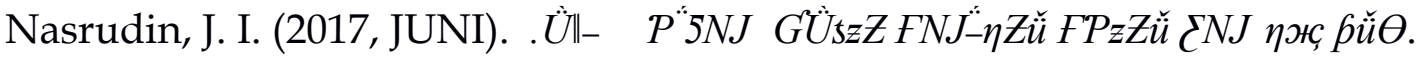
Diambil kembali dari :ان الع بي: http://lisanarabi.net/

Rahmat, I. (2017). Pembelajaran Bahasa Arab Dengan Pemanfaatan Teknologi. Jurnal Arabiyatuna, 1(2).

لأ ناذ ز ني. TNJ

ينش. ( غسطس 201820معلم اللغ العر ية بمد سة الإسلامي الأزهر قاهرة بلمبان ـ (د ا كينة، المحاو )

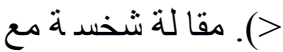

لَ. (أغد س, 201820قا لة مع لبة لمدرسة الـ انوية الإسلامب الأز هر قا رة بالمبنج. (دي سكية، المحاو )

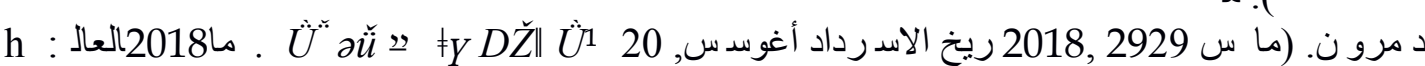
ن ن موضوع كبر وقع ربي ردttp:/ / mawdoo3.com

ضد ع. Mei, 2929)

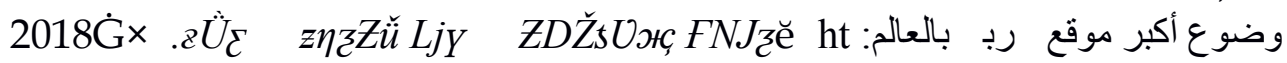
http://mawdoo3.com 